\title{
Biospecimen Events Supplemental Qualifiers Dataset
}

National Cancer Institute

\section{Source}

National Cancer Institute. Biospecimen Events Supplemental Qualifiers Dataset. NCI

Thesaurus. Code C147187.

A dataset containing supplemental information, specifically non-standard variables, to parent records in the biospecimen events domain. 